\title{
Microaggressions, Accountability, and Our Commitment to Doing Better
}

\author{
Samir S Shah, MD, MSCE ${ }^{1 *}$, Kimberly D Manning, MD², Charlie M Wray, DO, MS³, Angela Castellanos, MD4, \\ Karen E Jerardi, MD, MEd'
}

'Division of Hospital Medicine, Cincinnati Children's Hospital Medical Center and the Department of Pediatrics, University of Cincinnati College of Medicine, Cincinnati, Ohio; ${ }^{2}$ Department of Medicine, Emory University, Atlanta, Georgia; ${ }^{3}$ University of California, San Francisco, and San Francisco Veterans Affairs Medical Center, San Francisco, California; ${ }^{4}$ Department of Pediatrics, Tufts Children's Hospital, Tufts University School of Medicine, Boston, Massachusetts.

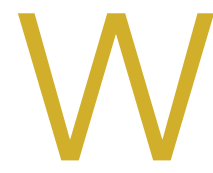
e recently published an article in our Leadership \& Professional Development series titled "Tribalism: The Good, the Bad, and the Future." Despite pre- and post-acceptance manuscript review and discussion by a diverse and thoughtful team of editors, we did not appreciate how particular language in this article would be hurtful to some communities. We also promoted the article using the hashtag "tribalism" in a journal tweet. Shortly after we posted the tweet, several readers on social media reached out with constructive feedback on the prejudicial nature of this terminology. Within hours of receiving this feedback, our editorial team met to better understand our error, and we made the decision to immediately retract the manuscript. We also deleted the tweet and issued an apology referencing a screenshot of the original tweet. ${ }^{1,2}$ We have republished the original article with appropriate language. ${ }^{3}$ Tweets promoting the new article will incorporate this new language.

From this experience, we learned that the words "tribe" and "tribalism" have no consistent meaning, are associated with negative historical and cultural assumptions, and can promote misleading stereotypes. ${ }^{4}$ The term "tribe" became popular as a colonial construct to describe forms of social organization considered "uncivilized" or "primitive. " In using the term "tribe" to describe members of medical communities, we ignored the complex and dynamic identities of Native American, African, and other Indigenous Peoples and the history of their oppression.

The intent of the original article was to highlight how being part of a distinct medical discipline, such as hospital medicine or emergency medicine, conferred benefits, such as shared identity and social support structure, and caution how this

*Corresponding Author: Samir S Shah, MD, MSCE; E-mail: Samir.Shah@ cchmc.org; Twitter: @SamirShahMD.

Published online first May 21, 2021

Received: May 6, 2021; Accepted: May 6, 2021

๑ 2021 Society of Hospital Medicine DOI 10.12788/jhm.3646 group identity could also lead to nonconstructive partisan behaviors that might not best serve our patients. We recognize that other words more accurately convey our intent and do not cause harm. We used "tribe" when we meant "group," "discipline," or "specialty." We used "tribalism" when we meant "siloed" or "factional."

This misstep underscores how, even with the best intentions and diverse teams, microaggressions can happen. We accept responsibility for this mistake, and we will continue to do the work of respecting and advocating for all members of our community. To minimize the likelihood of future errors, we are developing a systematic process to identify language within manuscripts accepted for publication that may be racist, sexist, ableist, homophobic, or otherwise harmful. As we embrace a growth mindset, we vow to remain transparent, responsive, and welcoming of feedback. We are grateful to our readers for helping us learn.

Disclosures: The authors have no conflicts to disclose.

\section{References}

1. Shah SS [@SamirShahMD]. We are still learning. Despite review by a diverse group of team members, we did not appreciate how language in.... April 30, 2021. Accessed May 5, 2021. https://twitter.com/SamirShahMD/status/1388228974573244431

2. Journal of Hospital Medicine [@JHospMedicine]. We want to apologize. We used insensitive language that may be hurtful to Indigenous Americans \& others. We are learning.... April 30, 2021. Accessed May 5, 2021. https:// twitter.com/JHospMedicine/status/1388227448962052097

3. Kanjee Z, Bilello L. Specialty silos in medicine: the good, the bad, and the future. J Hosp Med. Published online May 21, 2021. https://doi.org/10.12788/ jhm.3647

4. Lowe $\mathrm{C}$. The trouble with tribe: How a common word masks complex African realities. Learning for Justice. Spring 2001. Accessed May 5, 2021. https:// www.learningforjustice.org/magazine/spring-2001/the-trouble-with-tribe

5. Mungai C. Pundits who decry 'tribalism' know nothing about real tribes. Washington Post. January 30, 2019. Accessed May 6, 2021. https://www. washingtonpost.com/outlook/pundits-who-decry-tribalism-know-nothingabout-real-tribes/2019/01/29/8d14eb44-232f-11e9-90cd-dedb0c92dc17_ story.html 